\title{
OS JOGOS PAN-AMERICANOS RIO/2007 E O AGENDAMENTO MIDIÁTICO-ESPORTIVO: UM ESTUDO DE RECEPÇÃO COM ESCOLARES'
}

\author{
MS. CRISTIANO MEZZAROBA \\ Mestre em Educação Física pela Universidade Federal de Santa Catarina (CDS/UFSC) \\ Professor Departamento de Educação Física da Universidade Federal de Sergipe \\ (Aracaju - Sergipe - Brasil) \\ LaboMídia - Laboratório e Grupo de Estudos Observatório de Mídia Esportiva (UFSC) \\ e-mail: cristiano_mezzaroba@yahoo.com.br

\section{DR. GIOVANI DE LORENZI PIRES} \\ Professor do Departamento de Educação Física da Universidade Federal de Santa Catarina \\ (Florianópolis - Santa Catarina - Brasil) \\ Doutor em Educação Física pela Universidade Estadual de Campinas (UNICAMP) \\ LaboMídia - Laboratório e Grupo de Estudos Observatório de Mídia Esportiva (UFSC) \\ e-mail: giovanipires@cds.ufsc.br
}

\section{RESUMO}

Nesta pesquisa, caracterizada como estudo de recepção, analisamos como jovens estudantes compreendem e interpretam as estratégias de agendamento dos Jogos Pan-americanos Rio/2007. Para analisar os questionários-recordatários, os dados transcritos dos grupos de dis-

I. O presente trabalho contou com apoio financeiro da CAPES. 
cussão e também do diário de campo, fizemos uso das técnicas da análise de conteúdo. Foram identificadas cinco categorias: Personagens do Pan, Infraestrutura e Segurança, Variedades, Tocha Pan-americana e Contagem Regressiva. Por fim, consideramos adequado sugerirmos o desenvolvimento de mídia-educação no âmbito escolar, em especial na Educação Física, a fim de ampliar as compreensões que envolvem a cultura esportiva dos alunos.

PALAVRAS-CHAVE: Estudo de recepção; agendamento esportivo; Jogos Pan-americanos Rio-2007; educação física escolar.

\section{CONSIDERAÇÕES INICIAIS}

O fenômeno esportivo configura-se como um dos fenômenos mais marcantes e complexos da sociedade contemporânea. Sua importância decorre em grande parte pela difusão promovida pela mídia, por sua capacidade de construir sentidos e significados no interior de cada cultura.

Com relação à Educação Física mais especificamente, entendida como uma área de intervenção pedagógica, a mídia influencia os entendimentos a respeito das diversas práticas corporais, transformando aquilo que seria a cultura corporal de movimento (BETTI, 2003) em outras formas de consumo, ou, ainda, modificando as formas de perceber/praticar/analisar o esporte, considerado o conteúdo hegemônico das aulas de Educação Física.

Pelas suas características e pela capacidade de atrair telespectadores de todas as idades, nacionalidades, níveis de instrução e de condição social, e com isso patrocinadores, o esporte passou a ser um bem sucedido investimento financeiro, uma fonte inesgotável de notícias, de público e de lucro (KENSKI, 1995), tornandose, conforme Pires (2002, p. 90) "o parceiro preferencial da espetacularização na mídia televisiva".

E é por meio da realização e veiculação dos grandes eventos esportivos que cada vez mais o esporte se (tele)espetaculariza, nas mais variadas mídias, mas principalmente na televisão. Assim, pensando num grande evento esportivo de proporção continental, que foi os Jogos Pan-americanos Rio/2007 (JPA/2007), é que este estudo objetivou melhor compreender a questão da recepção midiática com jovens, os quais ficam sob a responsabilidade pedagógica do professor de Educação Física quanto aos assuntos pertinentes a este componente curricular.

Como questões norteadoras, elencamos as seguintes:

- Os contextos sócio-culturais nos quais os jovens se inserem têm influência na compreensão do discurso midiático-esportivo referente aos JPA Rio/2007? 
- Os jovens percebem interesses implícitos nos discursos, como a questão do consumo, a mercadorização/espetacularização do esporte, a utilização política dos Jogos, estratégias de criação de ídolos e os tensionamentos da relação local/global?

- Quais as possíveis interações desses discursos com a prática pedagógica da Educação Física, como componente curricular integrado ao projeto político-pedagógico da escola?

Pela segunda vez realizado no Brasil, na sua I $5^{a}$ edição, na cidade do Rio de Janeiro (RJ), o evento reuniu quarenta e dois países do continente americano e possibilitou uma discussão e reflexão em torno do fenômeno esportivo na contemporaneidade - as representações do esporte, os sentidos e significados que the são atribuídos e vinculados pelo discurso midiático, o que a população pensa a respeito do tema, entre outras questões.

A Educação Física Escolar brasileira, tendo no esporte seu conteúdo hegemônico, não poderia negligenciar este importante momento histórico do esporte nacional, já que a organização e realização de tal evento foi tida como um dos "degraus" para que o país se credenciasse melhor para almejar ser sede de outros eventos como a Copa do Mundo de Futebol/20 4 e os Jogos Olímpicos/2016.

que se viu, em meio a todo processo, principalmente nos meses anteriores à sua realização, foi um alto investimento na organização de tais jogos e, junto a isto, uma forte tematização prévia do mesmo nos mais variados veículos midiáticos, principalmente na televisão, com programação exclusiva referente aos JPA, características do que se pode denominar como um processo de "agendamento".

Segundo Traquina (200 I), o conceito de agendamento é apenas uma tradução do agenda-setting no inglês, e a sua ideia básica é a seguinte: "a capacidade da mídia em influenciar a projeção dos acontecimentos na opinião pública confirma o seu importante papel na figuração da nossa realidade social, isto é, de um pseudoambiente, fabricado e montado quase que completamente a partir dos mass mídia" (MCCOMBS; SHAW, 1977, apud TRAQUINA, 200 I, p. I4).

Pode-se dizer que o agendamento é um processo relacional entre a agenda jornalística (midiática) e a agenda pública (social), em que há uma tentativa de alguns grupos (financeiros, políticos e midiáticos) em pautar temas e assuntos de seu interesse na esfera social e colocar, desta maneira, sua(s) opinião(ões) com o objetivo de torná-la(s) hegemônica(s). O agendamento, portanto, é sempre exercido pela mídia, veículo que opera tais interesses, mas em estreita interação com a opinião 
pública, assim como com grupos privados ou da esfera pública, fazendo com que, em sua operacionalização, vários campos² se cruzem.

Diante disso, era necessário, também, pensar nas repercussões deste grande evento esportivo no que se refere à Educação Física escolar, ou seja, a apropriação, pelos alunos, das representações apresentadas e reforçadas pela mídia. Para que se chegue a qualquer tentativa de resposta, é necessário que se saiba mais sobre os receptores ${ }^{3}$, isto é, os jovens estudantes, entendendo-os como participantes de várias instituições, neste caso, especificamente, da instituição escolar, que realiza a chamada "mediação escolar".

Ao aproximar a temática esportiva veiculada pelos mais diversos veículos midiáticos, o professor de EF poderá inserir este componente curricular no processo de mídia-educação (BELLONI, 200 I ; FANTIN, 2006), aprofundando conhecimentos a respeito da mídia em geral para abordá-los nas suas aulas, dando um enfoque mais crítico ao esporte e aos seus demais conteúdos.

Considerando o evento esportivo (JPA/2007) como uma produção midiática, mas entendendo também o seu potencial pedagógico, é que esta pesquisa se destinou a investigar a recepção dos jovens estudantes de uma escola de Florianópolis/SC, identificando, analisando e compreendendo a construção discursiva deste evento que deu início ao que podemos denominar "a década dos mega-eventos esportivos no Brasil".

Na sequência do texto, portanto, contextualiza-se o estudo e explicitam-se as representações que a mídia gerou e que foram percebidas pelos estudantes, sendo compreendidas a partir de seus múltiplos contextos sócio-culturais de recepção.

\section{CARACTERIZAÇÃO DO ESTUDO, OBJETIVOS E ASPECTOS METODOLÓGICOS}

Este estudo, de abordagem qualitativa e do tipo descritivo (GOLDENBERG, 2005), caracterizou-se como um estudo de recepção (de acordo com a Corrente Latino-americana da Sociologia da Comunicação) e teve por objetivo analisar como

2. Segundo Bourdieu (1997, p. 57), campo "é um espaço social estruturado, um campo de forças - há dominantes e dominados, há relações constantes, permanentes, de desigualdade, que se exercem no interior desse espaço - que é também um campo de lutas para transformar ou conservar esse campo de forças."

3. Não desconhecemos as diferenças significativas dos diferentes processos de recepção em função das especificidades dos diversos veículos midiáticos. Por exemplo, sabemos que a internet permite uma interatividade que outros meios não permitem. No entanto, neste estudo, consideraremos para todos os efeitos recepção como processo geral de percepção, apropriação e (re)significação das mensagens midiáticas. 
os jovens percebem, compreendem e interpretam o agendamento midiático destes JPA, com possíveis repercussões disso na Educação Física Escolar.

Assim, considerando-se a Educação Física Escolar como uma intervenção pedagógica que faz sua mediação, e essa relação tão próxima entre esporte e mídia atualmente, o seguinte problema de pesquisa foi elaborado: como os jovens estudantes expressam a sua compreensão a respeito do discurso midiático-esportivo que agendou os JPA no Brasil em 2007?

Pautamos nossa discussão fundamentados pelos princípios dos Estudos de Mediação (MARTíN-BARBERO, 2003), e na Dialética das Múltiplas Mediações (OROZCO, 1993), isso porque constatamos que vem sendo desenvolvidos diversos estudos $^{4}$ no Brasil, com ênfase geralmente no polo emissor (mídia), pouco considerando os sujeitos que recebem e ressignificam tais produções (a recepção).

A pesquisa de campo foi realizada com um pequeno grupo de alunos de uma escola ${ }^{5}$ de Florianópolis, que constituíram um grupo de discussão, sendo desenvolvida através da coleta de questionários-recordatários e encontros periódicos com o grupo (grupos de discussão), fazendo-se uso também de um diário de campo.

Tal grupo foi acompanhado por um período de quarenta e dois dias, desde o dia primeiro de junho de 2007 (faltando um mês e meio para o início dos JPA/2007) até o dia treze de julho de 2007 (dia da abertura dos JPA/2007). Durante este período, foram realizados cinco encontros com o pequeno grupo, com duração variável entre uma hora e uma hora e meia, a fim de recolher os questionáriosrecordatários e também de realizar o grupo de discussão (momento em que o pesquisador apresentava algumas questões contidas em um roteiro elaborado previamente para discutir com o grupo de alunos sobre os JPA Rio/2007, sendo tais discussões gravadas no formato áudio).

Os questionários-recordatários ${ }^{6}$ eram entregues aos alunos para serem preenchidos durante a semana e devolvidos no encontro seguinte. No total, foram

4. Ver Azevedo, Costa e Pires (2008).

5. A escola caracteriza-se por ser uma instituição de ensino particular, localizada na região central de Florianópolis e que possui uma clientela com bom nível sócio-econômico (classe média). Não dispõe de muito espaço (por estar entre dois condomínios residenciais) principalmente no que se refere aos espaços da Educação Física, por possuir apenas uma pequena quadra coberta.

6. Para o preenchimento do questionário-recordatário, havia um espaço destinado ao local onde o aluno/sujeito viu/ouviu determinada informação referente aos JPA/Rio-2007 e ao lado deveria preencher o que havia visto/se informado, ou seja, a notícia/informação em si - isso durante todos os dias da semana. Combinamos que tudo que fosse informado/noticiado pela mídia em geral sobre os JPA/Rio-2007 poderia ser transcrito para os questionários-recordatários, incluindo, inclusive, conversas informais (na escola, em casa, entre amigos etc.). 
vinte e dois questionários-recordatários que foram recolhidos durante o acompanhamento com os sujeitos.

Para sistematização e interpretação dos dados, foi adotado o procedimento de análise de conteúdo (BARDIN, s/d), o que permitiu relacionar o objeto em estudo com as questões teóricas na forma de categorias (conforme Quadro 2).

\section{APRESENTAÇÃO E DISCUSSÃO DOS DADOS}

Com a entrada no campo, na segunda quinzena de abril de 2007, detectamos que os alunos sabiam da realização deste grande evento esportivo em território brasileiro no ano de 2007, o que pressupõe que, naquele momento, o agendamento para os JPA, no mínimo, já havia conseguido tematizar o evento, principalmente através da televisão e internet, bastante citados pelos sujeitos.

Durante os quarenta e dois dias de acompanhamento com o pequeno grupo, no período de 01/06/2007 a 13/07/2007, constituído por seis alunos (apenas quatro deles tiveram participação efetiva em todo processo da coleta de dados), recolhemos vinte e dois questionários-recordatários e realizamos cinco encontros, os quais denominamos grupos de discussão ${ }^{7}$.

\section{BREVE CARACTERIZAÇÃO DOS SUJEITOS DA PESQUISA E RELAÇÕES COM AS MEDIAÇÕES}

Para melhor conhecer os sujeitos da pesquisa, aplicou-se um questionário elaborado pelos pesquisadores, com questões abertas e fechadas (vinte e quatro no total), na tentativa de identificar e compreender de forma um pouco mais aprofundada algumas das suas estruturas de mediações (familiar, escolar, situacional e tecnológica).

Por se tratar de um grupo reduzido de sujeitos participantes e pelo caráter descritivo deste estudo, optamos em descrever os dados sem recorrer a valores percentuais, já que o pequeno grupo estudado está situado num determinado

7. Nos encontros realizados (semanalmente ou quinzenalmente), fazia-se um pequeno círculo, deixando um gravador de voz ao centro para registro de tudo que era tratado ou discutido, já que havia consentimento de todos para tais gravações. Os grupos de discussão eram previamente organizados pelo pesquisador, ou seja, havia um roteiro a ser discutido em cada encontro, discussões estas que permitiam, em seguida, a transcrição das conversas que constituíram, junto com os dados dos questionários-recordatários e do diário de campo, os dados empíricos desta pesquisa. Para saber mais, inclusive sobre os roteiros elaborados e a realização dos grupos de discussão, ver Mezzaroba (2008). 
contexto bastante específico e o propósito desta pesquisa não foi a generalização, mas sim a compreensão do contexto aos quais os sujeitos fazem parte.

Para se chegar aos sujeitos da pesquisa que compuseram o grupo de discussão, participaram, na primeira etapa da pesquisa, trinta e dois alunos da 9a série, com média de idade de 13,6 anos, sendo onze meninas e vinte e um meninos. No decorrer da pesquisa, o grupo iniciou com seis jovens, cinco meninos e uma menina, mas que de maneira efetiva teve a participação de quatro meninos no processo todo, com média de idade de 13 anos - coincidentemente a formação definitiva deste pequeno grupo que compõe a parte empírica desta pesquisa foi formada pelos 4 sujeitos que na primeira etapa da pesquisa foram escolhidos por terem demonstrado maior conhecimento sobre os JPA Rio/2007.

De forma esquemática e resumida, as mediações familiar e escolar dos sujeitos investigados caracterizam-se da seguinte maneira, conforme o quadro abaixo:

Quadro I - Resumo esquemático das mediações familiar e escolar dos sujeitos investigados

\begin{tabular}{|c|c|}
\hline MEDIA & IEDIAÇÃO ESCOLAR \\
\hline $\begin{array}{l}\text { - Todos têm mais que um aparelho de tv em } \\
\text { casa, sendo que apenas I deles não têm tele- } \\
\text { visão no quarto; } \\
\text { - Assistem televisão aberta (3 canais) e também } \\
\text { televisão paga (todos citam canais esportivos); } \\
\text { •Todos dizem assistir a noticiários e programas/ } \\
\text { transmissões esportivas; } \\
\text { - Assistem sozinhos ou, quando acompanhados, } \\
\text { geralmente pelos pais; } \\
\text { - Todos fazem bastante uso do computador } \\
\text { em casa, com internet a cabo (além de terem } \\
\text { acesso à internet fora de casa também) e parti- } \\
\text { cipam de redes de relacionamento (predomínio } \\
\text { do orkut); } \\
\text { - Costumam conversar com pais, irmãos e } \\
\text { amigos sobre o que encontram na internet; } \\
\text { - Tem acesso a revistas e jornais, apesar de } \\
\text { que isso não significa que leem (segundo suas } \\
\text { respostas). }\end{array}$ & $\begin{array}{l}\text { - Usam internet na escola (quase todos men- } \\
\text { cionaram); } \\
\text { - O "professor" foi citado duas vezes como } \\
\text { alguém com quem eles costumam conversar } \\
\text { os conteúdos encontrados na internet; } \\
\text { - Na escola não se costuma utilizar a televisão } \\
\text { como um recurso durante as aulas (todos res- } \\
\text { ponderam que "não"); } \\
\text { - Nas aulas de Educação Física também não } \\
\text { se oportuniza este momento, e quando se faz, } \\
\text { faz-se como "ferramenta" (exibir vídeo sobre } \\
\text { determinada modalidade); } \\
\text { - Os alunos responderam que veem a pos- } \\
\text { sibilidade de se utilizar tais recursos nas aulas } \\
\text { de Educação Física, apesar de uma visão ainda } \\
\text { restrita de como se daria essa utilização; } \\
\text { - A escola tem laboratório de informática, mas } \\
\text { parece que seu uso ainda é pequeno e limitado, } \\
\text { especialmente para Educação Física. }\end{array}$ \\
\hline
\end{tabular}




\section{O ACOMPANHAMENTO FEITO POR MEIO DOS QUESTIONÁRIOS- RECORDATÁRIOS}

Em síntese, podemos dizer que predominantemente houve uma utilização dos veículos televisão e internet na obtenção e no acompanhamento de notícias referentes aos JPA/2007. No caso da televisão, houve um forte predomínio da Rede Globo e da SporTV; e no caso da internet, predomínio de conteúdos presentes em sites do Grupo Globo (globo.com e globoesporte.com), além de outros sites citados.

Dentre os programas mencionados pelos sujeitos, o Globo Esporte, programa esportivo diário veiculado no horário do meio-dia e de grande audiência em todo Brasil, foi o que mais recebeu citações, cinquenta e cinco vezes.

Percebemos também a ausência de menções a outros veículos, principalmente os de mídia impressa (como jornais e revistas), o rádio e até mesmo outras emissoras de televisão que poderiam ter em sua transmissão um discurso diferenciado em relação às três emissoras que foram citadas pelos sujeitos (Globo, SporTV e Band).

\section{AS CATEGORIAS EXTRAÍDAS NA TRIANGULAÇÃO DOS DADOS: DESCRIÇÃO E ANÁLISE}

Na segunda etapa da pesquisa, ao analisar os dados e fazer a triangulação dos mesmos a partir dos questionários-recordatários, das transcrições dos grupos de discussão e do diário de campo, identificamos cinco categorias de análise: Personagens do Pan, Infra-estrutura e segurança, Tocha Pan-americana, Contagem regressiva e Variedades - que foram, a nosso ver, a maneira como a mídia, principalmente a televisiva, promoveu o agendamento para os JPA/2007 segundo os escolares pesquisados.

Extraídas do campo, essas categorias podem ser identificadas como uma síntese das principais estratégias de agendamento dos JPA empregadas pela mídia que foram identificadas e às quais foram atribuídos significados, no processo de recepção ao discurso midiático-esportivo, pelos jovens estudantes. É provável que outros mecanismos de agendamento tenham sido mobilizados pela mídia, ainda que no presente estudo estas tenham sido as que foram detectadas e destacadas pelos sujeitos da recepção.

Essa observação contribui para a reflexão quanto ao principal objetivo deste estudo, que foi compreender como os estudantes expressam a sua compreensão a respeito do discurso midiático-esportivo promovido para o agendamento dos JPA/2007. Assim, preliminarmente, podemos inferir que, de forma geral, a percepção dos alunos é bastante ampla e precisa, capaz de identificar nestes cinco eixos - aqui consideradas como categorias de análise - os caminhos pelos quais, repetidamente, ao 
longo do período acompanhado, os meios os utilizaram para inscrever previamente, na agenda social e esportiva do país, a realização dos Jogos no Brasil.

No Quadro 2 apresentamos e caracterizamos as categorias; a partir daí, procedemos uma discussão mais ampla e generalizada sobre as mesmas ${ }^{8}$.

Quadro 2 - Identificação e apresentação das categorias

\begin{tabular}{|c|c|}
\hline $\begin{array}{c}\text { Personagens } \\
\text { do Pan }\end{array}$ & $\begin{array}{l}\text { Refere-se aos registros que informavam sobre o treinamento feito } \\
\text { para disputar o Pan e as preocupações anteriores ao evento, ou seja, } \\
\text { aspectos relacionados ao caráter técnico da preparação, principal- } \\
\text { mente aos dos atletas brasileiros. }\end{array}$ \\
\hline Infraestrutura e segurança & $\begin{array}{l}\text { Informações que se referiam aos aspectos da infra-estrutura (as } \\
\text { obras e a preocupação com atraso, o sistema de transporte na } \\
\text { cidade do Rio de Janeiro) e segurança do evento (preocupação } \\
\text { com a violência e com a polícia). }\end{array}$ \\
\hline Tocha Pan-americana & $\begin{array}{l}\text { Categoria constituída com as informações que fizeram o acompanha- } \\
\text { mento do percurso da tocha dos JPA pelas cidades brasileiras, desde } \\
\text { seu acendimento no México até o acendimento da pira no dia da } \\
\text { abertura do evento na cidade do Rio de Janeiro. }\end{array}$ \\
\hline $\begin{array}{l}\text { Contagem } \\
\text { Regressiva }\end{array}$ & $\begin{array}{l}\text { Categoria formada pelas informações que desde o primeiro dia de } \\
\text { preenchimento do questionário-recordatário }(02 / 06) \text { até o último } \\
\text { dia (13/07) se referiam aos dias que faltavam para a abertura dos } \\
\text { JPA/2007. }\end{array}$ \\
\hline Variedades & $\begin{array}{l}\text { Categoria formada por uma variedade de informações, dos mais } \\
\text { diversos temas, (aspectos históricos dos Jogos, política, moda, } \\
\text { uniformes, hino, tabela de disputas, a chegada de atletas na Vila e as } \\
\text { movimentações por lá, casos de doping, o início dos Jogos, além de } \\
\text { curiosidades em geral). }\end{array}$ \\
\hline
\end{tabular}

8. A discussão por categoria será abreviada em virtude do espaço disponível nas normas da revista. 


\section{I) PERSONAGENS DO PAN}

Dentre as cinco categorias constituídas, a categoria que aqui chamamos de Personagens do Pan foi a que mais recebeu menções dos sujeitos pesquisados, totalizando cento e vinte notícias relatadas pelos alunos no acompanhamento do discurso midiático-esportivo relacionado aos JPA/2007. Refere-se aos registros que informavam sobre o treinamento feito para disputar o Pan e as preocupações anteriores ao evento, ou seja, aspectos relacionados ao caráter técnico da preparação, com ênfase nos atletas brasileiros.

A mídia, principalmente os veículos televisão e internet, que predominaram nas respostas dos sujeitos da pesquisa (com quase 98\% das referências), tem como uma de suas primeiras estratégias, ao pautar um acontecimento ou evento, como no caso dos JPA/2007, apresentar e situar os seus protagonistas, isto é, os personagens da notícia, seus nomes, expectativas, dramas pessoais, criando assim um vínculo entre os espectadores/torcedores com os personagens do evento que aconteceria a seguir.

No caso específico dos atletas brasileiros, pudemos constatar que houve uma ênfase naqueles que são mais conhecidos pelo público em geral, como por exemplo: Bernardinho (técnico de vôlei), Ricardo e Emanuel (vôlei de praia), Janeth (basquete), Rodrigo Pessoa (hipismo), Daiane dos Santos (ginástica), Guga (tênis), Jardel Gregório (salto triplo), Maureen Maggi (salto em distância) e Marta (futebol feminino).

Podemos dizer que se o agendamento é uma forma como a mídia, em seu conjunto e à sua maneira tem em apresentar ao público sobre aquilo que é necessário ter uma opinião e discutir (TRAQUINA, 200 I), ao apresentar principalmente os atletas brasileiros que participariam dos JPA, os veículos midiáticos tiveram, entre tantas pretensões possíveis, ao menos duas que podemos discutir neste momento.

A primeira pretensão seria de criar uma identificação do público com os JPA/2007 a partir dos atletas brasileiros, e a segunda, embora o evento fosse realizado em solo brasileiro, da utilização daquilo que conhecemos por "dialética local/global" (PIRES et al., 2006), ou seja, a forma como a mídia local se utiliza de estratégias para vender/informar sobre um evento global, geralmente se identificando com características do local'.

9. Quanto aos quarenta e nove atletas catarinenses que estavam participando dos JPA/Rio-2007, os sujeitos da pesquisa demonstraram pouco conhecimento em relação a tais atletas "locais", talvez por dois motivos: ( I ) porque realmente a mídia local, ao ser acompanhada pelos sujeitos, não enfatizou os atletas do estado de Santa Catarina ou da cidade de Florianópolis; (2) ou pela baixa expectativa de bons resultados desses atletas. 
Percebemos, assim, que a discussão em relação a esta categoria nos remete às questões de personificação e ídolos. São eles, esses super-atletas, as celebridades do mundo esportivo na qual sua veiculação caracteriza-se como uma das principais estratégias da mídia para dar inteligibilidade ao acontecimento e também porque, ao apresentar ao público informações dos principais atletas, a mídia acaba estimulando o torcedor a torcer pelo seu ídolo, tendo, em sua figura, a esperança do êxito, constatação esta corroborada por Marchi Júnior (200 I , p. I39) ao afirmar que:

Comumente, à mídia é atribuída a função de aproximar os leitores e telespectadores dos eventos esportivos aos principais personagens que compõem o espetáculo esportivo, ou seja, os atletas. Esses, por sua vez, transformam-se rapidamente em ídolos e transmissores de mensagens e estereótipos, dotados de um potencial de consumo enraizado na cultura esportiva de massas.

De acordo com nossa interpretação, ao considerar o conjunto das estratégias realizadas pelo discurso midiático-esportivo na realização do agendamento para os JPA/2007, entendemos que a mídia, ao informar aspectos técnicos do treinamento para o referido evento e as delegações participantes, enfatizou os ídolos esportivos, à maneira da falação esportiva (ECO, 1984; BETTI, 1998) numa tentativa de chamar a atenção do público brasileiro e, ao mesmo tempo, criar uma identificação com este.

\section{2) INFRAESTRUTURA E SEGURANÇA}

Esta categoria foi estabelecida a partir de setenta e três registros dos sujeitos pesquisados em seus questionários-recordatários, em função da ênfase nos aspectos da infraestrutura (obras e preocupação com os atrasos; o sistema de transporte e os congestionamentos) e segurança do evento (preocupação com violência e polícia).

Sabendo que uma das funções do agendamento realizado pela mídia é emergir e pautar fatos e que a partir disso serão discutidos e debatidos no cotidiano, acreditamos que para além de informar os aspectos da infraestrutura e segurança para os JPA/2007, uma das intenções foi a de criar uma interação com a opinião pública, fazendo o público acompanhar este "desfecho" das obras com uma expectativa (de torcedor), deixando um pouco de lado abordagens mais críticas, enfatizando apenas os gastos com o evento, a situação das obras e seu cronograma.

Percebeu-se aquilo que poderíamos chamar de "inversão de prioridades", por parte do governo federal, em favor da construção do "grande palco" para os JPA, opinião corroborada e ampliada pelo jornalista Juca Kfouri (2007), em entrevista publicada no site Observatório da Imprensa: 
O papel do Estado, principalmente em um país com as carências do Brasil, é promover o esporte como fator de saúde para a população brasileira. Esporte de alto rendimento não deve ser preocupação do Estado. O Estado tem que massificar o esporte, e naturalmente da quantidade sairá a qualidade. (...) O que há aqui é uma inversão. Não temos uma política esportiva para o país, não se pensa o esporte como fator de inclusão social, não se pensa o esporte como um fator de prevenção de doenças, e nós temos todas essas distorções.

Com relação ao "legado" do Pan, os sujeitos pesquisados em muitas ocasiões relataram informações que tinham como foco a construção da Vila Pan-americana, do Estádio João Havelange e demais equipamentos esportivos construídos para este evento, informações estas com caráter crítico quanto ao atraso nas obras. Entretanto, o que se viu foi um reducionismo em relação a esta questão, pois considerando-se um evento desta envergadura e a necessidade de reestruturação urbanística da cidade do Rio de Janeiro, mais investimentos deveriam ter sido efetivados conforme previsto no projeto original dos JPA/2007: entre outros, a nova linha de metrô, saneamento da baía de Guanabara e da Lagoa Rodrigo de Freitas.

Outra discussão quanto a esta categoria foram os investimentos feitos para a realização dos JPA como um passaporte o país sediar eventos esportivos de dimensões globais, como a Copa do Mundo/2014 e também a possibilidade do RJ ser a cidade brasileira sede das Olimpíadas/20 16. Sobre tais possibilidades do Brasil sediar megaeventos esportivos, Nozaki e Penna (2007) afirmam que:

o discurso comum ao governo federal e aos órgãos ligados à organização do Pan é o da necessidade do sucesso de sua organização e sua realização para que este seja uma porta para eventos de maior porte, posto os anseios de sediar a Copa do Mundo de Futebol de 2014. Ou seja, a realização do Pan se justifica, para estes casos, na busca de realização de eventos maiores, portanto, abre-se a necessidade infindável da realização destes eventos como uma forma impulsionadora da economia e do desenvolvimento do próprio esporte.

Consideramos com isso, que a mídia, ao apresentar principalmente a crítica ao atraso das obras para o evento esportivo, acabou criando uma expectativa nos torcedores, em torno da pergunta "será que vai ficar pronto?", ao mesmo tempo em que ia familiarizando o público com os locais das disputas esportivas. Evidenciouse, também, que as críticas apresentadas pelos pesquisados não foram além das próprias críticas apresentadas pelos veículos midiáticos os quais acompanharam, sem apresentar muita profundidade.

\section{3) TOCHA PAN-AMERICANA E A CONTAGEM REGRESSIVA}

Dentre todas as estratégias de agendamento realizadas pelo discurso midiático-esportivo em relação aos JPA/2007, talvez as que foram mais visíveis 
tenham sido o acompanhamento da tocha Pan-americana pelo território brasileiro e a contagem regressiva que se fez dia a dia para a abertura oficial dos JPA. Tanto a primeira como a segunda foram identificadas pelos pesquisados, as quais acabaram originando duas categorias: Tocha Pan-americana ${ }^{10}$ (funcionou como uma forma de mobilização da mediação cultural, conforme Martín-Barbero (2003), com a intenção de criar uma identificação nacional do público com o evento que aconteceria em seguida, numa dialética local/global) e contagem regressiva (notícias que contavam os dias que faltavam até a abertura dos JPA).

A passagem da tocha pan-americana se revezava pelas diversas cidades brasileiras, conferindo um discurso de integração nacional, fazendo-se uso de atletas locais de destaque como também de outras celebridades locais, cujo objetivo, supomos, seria chamar atenção do público e criar uma identificação do evento com a população de cada região. Acreditamos que a Rede Globo (por ter sido a emissora mais citada pelos sujeitos) tenha criado o slogan "O Pan do Brasil", ajudando a "vender" o evento, de acordo com o que foi expressado por Bucci (1 998) citado por Pires (2002): a mídia como promotora e divulgadora dos JPA/2007. Tal estratégia foi identificada pelos sujeitos pesquisados, apesar de saberem que o nome do evento era "Jogos Pan-americanos Rio-2007".

Ao mesmo tempo em que isto acontecia, o agendamento para o grande evento esportivo ocorria também por meio da própria virada de página, ou seja, o agendamento em seu sentido manifesto, em que, no dia a dia das pessoas, a mídia, de forma geral, procurava apresentar, de forma regressiva, o número de dias que ainda faltavam para o início dos JPA.

Considerando-se que o conceito de agendamento nos diz que a mídia oferece ao público temas para pensar e discutir, projetando um evento e buscando, com isso, uma interação com a opinião pública (TRAQUINA, 200 I), tendo, portanto, o pressuposto da questão temporal (longo prazo) e que seus efeitos se dão de forma acumulativa, vimos que aos poucos o evento foi sendo colocado pela mídia como algo que iria acontecer futuramente em território brasileiro, atraindo as atenções de todos, associando a tocha pan-americana aos aspectos turísticos/históricos das cidades, personalidades, gastronomia etc., e a contagem regressiva ao acompanhamento público da contagem, mobilizando o imaginário social.

10. Categoria que circulou em torno das notícias que fizeram o acompanhamento do percurso da tocha dos JPA, desde o acendimento do fogo simbólico, em 04/06/2007, até o acendimento da pira Pan-americana no Rio de Janeiro, no dia 13/07/2007. 
Categoria que abarca uma variedade de informações, as quais não se enquadram nas demais categorias, como por exemplo, aspectos históricos dos Jogos, política, moda, uniformes, hino, tabela de disputas, a chegada de atletas e as movimentações na Vila Pan-americana, casos de doping, o início dos Jogos, além de curiosidades em geral que circularam em torno do que poderíamos chamar "notícias de entretenimento".

Através desta categoria podemos supor que o discurso midiático, composto por três dimensões - informação, entretenimento e publicidade - realmente segue a tendência de, cada vez mais, ter as fronteiras entre suas dimensões bem mais tênues, mesclando estes três elementos.

Quando este discurso midiático tem o esporte como tema principal - o discurso midiático-esportivo - o que se percebe é que as fronteiras entre informação, entretenimento e publicidade se suavizam ainda mais, talvez pela própria polissemia (BETTI, 1998) que o campo esportivo permite e também pela informalidade no trato de tais assuntos.

Percebemos que o programa mais referido pelos sujeitos da pesquisa foi o Globo Esporte " ', tornando-se uma referência quando querem se informar sobre os assuntos esportivos, algo que, segundo Orozco (2006, p. 88) pode ser chamado de "ritualidade comunicativa", ou seja, práticas comunicativas que geram hábitos e promovem regularidade nos sujeitos, os quais interiorizam comportamentos e modelos ou padrões de reações diante das referências comunicativas.

Além disso, em função dos sujeitos citaram a emissora Rede Globo com muita frequência e intensidade, e considerando sua hegemonia nacional quando se fala em mídia no Brasil, podemos fazer alusão ao que Bourdieu (1997) denomina de "circularidade circular da informação", pela constituição homogênea dos meios e sua veiculação para os mais variados tipos de audiência, considerando-os uma "massa homogênea".

Com relação às discussões em torno da publicidade, sinteticamente, podemos dizer que os sujeitos identificaram algumas empresas patrocinadoras dos JPA/2007 devido à sua veiculação principalmente na televisão e que os mesmos sabem do poder e da função da publicidade, mas consideram que nem sempre agem da forma como ela sugere.

I I. Tal programa é transmitido nacionalmente, em três blocos de exibição, sendo o primeiro voltado às informações regionais e os dois últimos compostos por informaç̃̃es destinadas à toda população brasileira. Tem como característica a linguagem informal, suas notícias possuem um teor divertido, com informações leves e descontraídas. 


\section{CONSIDERAÇÕES FINAIS}

O que foi percebido pelos pesquisados e se revela pelas categorias elaboradas neste estudo foram variadas estratégias de agendamento empregadas pela mídia, procurando articular diferentes campos e interesses que convergiam ao campo esportivo. Tais categorias seriam uma síntese das principais estratégias de agendamento para os JPA, mas acreditamos que outros mecanismos de agendamento também tenham sido mobilizados pela mídia.

Para analisá-las, consideramos que esta foi a forma como os sujeitos atribuíram significado e expressaram a sua compreensão a respeito do discurso midiáticoesportivo que agendou os JPA/2007, demonstrando uma percepção ampla e precisa, embora, como já apontado, apresentando superficialidade nas críticas, às vezes reproduzindo as abordagens feitas pelos meios.

Os sujeitos investigados perceberam a ênfase que a mídia atribuiu aos atletas considerados "mais famosos" do âmbito esportivo brasileiro, como uma forma de criar uma identificação com o público em geral e também de gerar expectativas de vitória, aproximando as questões de identificação cultural como um atrativo para se acompanhar o evento esportivo. Isto ficou mais claro com a identificação da categoria Personagens do Pan.

Outra estratégia identificada pelos sujeitos pesquisados e que aqui denominamos como Infraestrutura e Segurança se configurou em uma das estratégias do discurso midiático-esportivo (articulado com discursos econômicos, políticos e sociais), ao realizar o agendamento para os JPA/2007. Neste caso, as notícias veiculadas sobre os aspectos das construções/reformas de instalações esportivas para os JPA e os aspectos da segurança na cidade do RJ para o grande evento esportivo tinham como intenção criar uma interação com a opinião pública, fazendo o público acompanhar o desfecho das obras com bastante expectativa.

Talvez o acompanhamento da tocha Pan-americana pelo território brasileiro, articulado à contagem dos dias que faltavam para o início do evento, tenham sido as estratégias mais visíveis aos sujeitos pesquisados, o que nos faz pensar na questão da mobilização da mediação cultural, conforme Martín-Barbero (2003), em se tratando da categoria Tocha Pan-americana. A categoria Contagem Regressiva seria a representação simbólica do ato de "virar a página da agenda", contando os dias que faltavam até a abertura dos Jogos.

As notícias de entretenimento que veiculavam informações sobre os JPA/2007 também foram percebidas e relatadas pelos sujeitos da pesquisa, constituindo a categoria que denominamos Variedades, elaborada em função de notícias que "fofocavam" sobre o evento, além dos aspectos da publicidade dos Jogos. Sua presença 
permite observar que as fronteiras do discurso midiático realmente estão cada vez mais misturadas, mesclando informação, entretenimento e publicidade.

Apesar disso, podemos dizer que a questão da mercadorização do esporte, ou seja, o esporte como algo a ser vendido e consumido, não esteve muito presente nas falas dos sujeitos da pesquisa. Todavia, quando provocados a falar da publicidade e sua relação com o esporte e a mídia, os sujeitos foram capazes de identificar algumas empresas patrocinadoras do evento e demonstraram um certo conhecimento em relação aos objetivos da publicidade.

Entendemos que os resultados desta pesquisa apontam para a necessidade cada vez mais iminente da Educação Física, como componente curricular, tematizar as questões midiáticas em sua prática pedagógica, considerando-se que a mediação tecnológica se faz cada vez mais presente e intensa na vida dos jovens e que precisa ser confrontada com outros saberes, neste caso, o da Educação Física como campo de conhecimento. A realização dos JPA, neste caso (bem como dos próximos megaeventos esportivos no país), poderia ter sido um excelente momento para a Educação Física escolar tratá-lo como "conteúdo" na discussão e no acesso a novos conhecimentos quanto à cultura corporal de movimento.

Acreditamos, com isso, que é imprescindível que a Educação Física, tendo como um de seus conteúdos preferenciais o esporte, assuma sua responsabilidade com uma intervenção pedagógica que permita aos sujeitos um conhecimento mais amplo e mais crítico, fazendo uso daquilo que há muito tempo é propagado pela mídia-educação: uma educação que objetive contribuir na formação para de indivíduos com menos encantamento em relação à espetacularização promovida pela mídia, que lhes permita desenvolver maior autonomia, com um olhar mais atento e amplo aos acontecimentos da dinâmica cultural e da cultura esportiva.

Por fim, cabe perguntarmo-nos se a Educação Física deixou passar em branco um momento singular que foi a realização desses Jogos em território brasileiro e de tudo que aconteceu em função dele. Os dados deste trabalho, no caso específico observado, pelo menos apontam que sim.

Por isso, mais do que nunca é necessário que novas abordagens sejam incorporadas a este campo de conhecimento, e aqui estamos sugerindo, diante dos dados empíricos encontrados e da discussão que fizemos com a literatura, que a Educação Física passe a considerar seus alunos como sujeitos-receptores, sedentos de novas abordagens. Isso vai ao encontro das ideias de Orozco (I 997, p. 65), o qual considera que a "escola e os professores têm, junto ao enorme desafio que Ihes colocaram os MCM [Meios de Comunicação de Massa], um grande potencial para desenvolver." O processo é longo, mas necessário... em se tratando da mídia esportiva, a Copa do Mundo de 2014 e os Jogos Olímpicos de 2016 são excelentes oportunidades para fazê-lo. Pois bem, façamos! 


\section{The pan-american Rio/2007 games and the media-sports agenda: a reception study with scholars}

ABSTRACT: In this study, characterized as a reception study, we analyze how young students understand and interpret the scheduling strategies of the Pan American Rio/2007 Games' Agenda. To analyze the recall-questionnaires, the transcripted data of the discussion groups, as well as the field notes, we used the techniques of the content analysis. Were identified 5 categories: Pan Personalities, Infrastructure and Security, Variety, Pan American Torch and Countdown. Finally, we considered appropriate to suggest the development of the media education in schools, especially concerning Physical Education, to broaden the understandings that involve the sporting culture of the students.

KEYWORDS: Reception study; scheduling sports; Pan American Games Rio-2007; physical education.

\section{Los juegos panamericanos Río/2007 y el agendamiento mediático- deportivo: un estudio de recepción con escolares}

RESUMEN: En esta investigación, caracterizada como estudio de recepción, analizamos como los jóvenes estudiantes comprenden e interpretan las estrategias de agendamiento de los Juegos Panamericanos Río/2007. Para analizar los cuestionarios-recordatorios, los datos transcriptos de los grupos de discusión y también del diario de campo, hicimos uso de las técnicas de análisis de contenido. Fueron identificadas 5 categorías: Personajes del Panamericano, Infraestructura y Seguridad, Variedades, Antorcha Panamericana y Cuenta Regresiva. Finalmente, consideramos adecuado sugerir el desarrollo de la media-educación en el ámbito escolar, en especial en la Educación Física, con el fin de ampliar las comprensiones que envuelven la cultura deportiva de los alumnos.

PALABRAS CLAVE: estudio de recepción; agendamiento deportivo; Juegos Panamericanos Río-2007; educación física escolar.

\section{REFERÊNCIAS}

AZEVEDO, V.; COSTA, A.G.; PIRES, G. de L. Análise da produção em Educação Física/ Esporte e Mídia veiculada nos congressos do CBCE e da INTERCOM. In: CONGRESSO SULBRASILEIRO DE CIÊNCIAS DO ESPORTE, 4., 2008, Pinhão/PR. Anais... Pinhão/PR: CBCE, set/2008.

BARDIN, L. Análise de conteúdo. Lisboa: Edições 70, s/d.

BELLONI, M.L. O que é mídia-educação? Campinas: Autores Associados, 2001 .

BETTI, M. (Org.). Educação Física e mídia: novos olhares, outras práticas. São Paulo: Hucitec, 2003. 
BETTI, M. Janela de vidro: esporte, televisão e educação física. Campinas: Papirus, 1998. BOURDIEU, P. Sobre a televisão. Rio de Janeiro: Jorge Zahar, 1997.

ECO, U. A falação esportiva. In: - Viagem na irrealidade cotidiana. Rio de Janeiro: Nova Fronteira, 1984. p. 220-226.

FANTIN, M. Mídia-educação: conceitos, experiências, diálogos Brasil-Itália. Florianópolis: Cidade Futura, 2006.

GOLDENBERG, M. A arte de pesquisar: como fazer pesquisa qualitativa em Ciências Sociais. 9. Ed. Rio de Janeiro: Record, 2005.

KENSKI, V. M. O impacto da mídia e das novas tecnologias de comunicação na educação física. Revista Motriz, Rio Claro, v. I, n. 2, p. 129-134, dez. 1995.

KFOURI, J. Pauta para depois dos Jogos Pan-Americanos. Observatório da Imprensa, ano I2, n. 443, 24 jul. 2007. Disponível em: <http://observatorio.ultimosegundo.ig.com.br/artigos. asp?cod=443IMQ004 > . Acesso em: 22 out. 2007.

MARCHI JÚNIOR, W. "Sacando" o voleibol: do amadorismo à espetacularização da modalidade no Brasil (1970-2000). 200 I . 267 f. Tese (Doutorado em Educação Física). Faculdade de Educação Física, Universidade Estadual de Campinas, Campinas-SP, 2001.

MARTíN-BARBERO, J. Dos meios às mediações: comunicação, cultura e hegemonia. $2^{\mathrm{a}}$. Ed. Rio de Janeiro: UFRJ, 2003.

MEZZAROBA, C. Os Jogos Pan-americanos Rio/2007 e o agendamento midiático-esportivo: um estudo de recepção com escolares. 2008. I 53p. Dissertação (Mestrado em Educação Física - Teoria e Prática Pedagógica) - Centro de Desportos, Universidade Federal de Santa Catarina, Florianópolis, 2008.

NOZAKI, H. T.; PENNA, A. M. Jogos Pan-americanos Rio de Janeiro 2007: por trás das cortinas do grande espetáculo. Lecturas Educación Física y Deportes, Buenos Aires, ano 12, n. I I 0, jul. 2007. Disponível em: < http://www.efdeportes.com/efd I I0/jogos-pan-americanosrio-de-janeiro-2007.htm>. Acesso em: 22 out. 2007.

OROZCO, G.G. Hacia una dialéctica de la recepción televisiva: la estructuración de estrategias por los televidentes. Comunicação \& Política na América Latina, São Paulo, ano 8, v. 22 a 25, p. 57-73, 1993.

Professores e meios de comunicação: desafios, estereótipos. Comunicação e Educação, n. 10, p. 57-68, set-dez., 1997.

. Comunicação social e mudança tecnológica: um cenário de múltiplos desordenamentos. In: MORAES, D. de (Org.). Sociedade midiatizada. Rio de Janeiro: Mauad, p. $81-98,2006$. 
PIRES, G. De L. Educação física e o discurso midiático: abordagem crítico-emancipatória. ljuí: Unijuí, 2002.

PIRES, G. De L. et al. Catarinenses olímpicos na mídia impressa regional: a dialética local-global na cobertura dos Jogos Olímpicos de 2004. In: CONGRESSO SUL-BRASILEIRO DE CIÊNCIAS DO ESPORTE, 3., Santa Maria/RS, set. 2006. Anais... Santa Maria: CBCE, 2006.

TRAQUINA, N. O estudo do jornalismo no século XX. São Leopoldo: Unisinos, 2001 .

Recebido: 31 mar. 2010

Aprovado: $30 \mathrm{dez} .2010$

Endereço para correspondência:

Cristiano Mezzaroba

Rua Jordão de Oliveira, 96 - casa I I

Bairro Atalaia

Aracaju-SE

CEP: $49037-330$ 